\title{
KAJIAN KAPASITAS DAN TEBAL PERKERASAN PADA RUAS JALAN SUKANAGARA - TANGGEUNG KM BDG 136+000 - KM BDG 141+300 KABUPATEN CIANJUR
}

\author{
${ }^{1}$ Edi Suryadi , ${ }^{2}$ Yudi Sekaryadi \\ Program Studi Teknik Sipil Fakultas Teknik Universitas Suryakancana \\ edisuryadi76@gmail.com, yudisekaryadi65@gmail.com
}

\begin{abstract}
Abstrak
Seiring perkembangan jalan sebagai jaringan transportasi dan sebagai jaringan penghubung antar wilayah Cianjur Kota-Cianjur Selatan. Semakin meningkatnya pertumbuhan penduduk di kota - kota dan semakin banyak kendaraan telah berdampak kepada masalah lalu lintas sehingga di tuntut lebih dalam mengenai perkembangan jalan dan semakin kesini banyak menimbulkan masalah lalu lintas yaitu kerusakan jalan, seperti kondisi jalan yang retak - retak dan jalan berlubang pada ruas jalan di sekitar jalur Cianjur Selatan tepatnya jalan ruas Sukanagara sampai Tanggeung Km Bdg 136+000 - Km Bdg 141+300 Kabupaten Cianjur dengan kondisi jalan seperti itu, maka tidak menutup kemungkinan akan menyebabkan kecelakaan lalu lintas.

metode penyelesaian masalah pada laporan penelitian ini adalah mengumpulkan data primer dan data sekunder, yaitu berupa data perencanaan jalan dari proyek jalan Cianjur Kota-Cianjur Selatan (sesuai lokasi objek penelitian), data lalu lintas harian rata - rata (LHR), data CBR tanah dan buku - buku perkuliahan. Mencari penyebab permasalahan pada ruas jalan Sukanagara - Tanggeung KM BDG $136+000-K M B D G 141+300$. Mencari data yang di butuhkan untuk merencanakan tebal perkerasan pada ruas jalan Sukanagara - Tanggeung KM BDG 136+000 - KM BDG 141+300 seperti data CBR tanah dan LHR jalan. Kemudian merencanakan dan menghitung tebal perkerasan pada ruas jalan SukanagaraTanggeung KM BDG 136+000 - KM BDG 141+300 dengan menggunakan metode analisa komponen SNI $1732-1989-F$.

Dengan nilai derajat kejenuhan $D S=0.54$ (DS $\leq 0.6)$ seharusnya kecepatan perjalanan rata - rata $\geq 80$ $\mathrm{km} / \mathrm{jam}$. Karena FVLV $=33.81 \mathrm{~km} / \mathrm{jam}$, maka pada ruas jalan tersebut perlu diperlebar..Tebal perkerasan lentur yang dihitung dengan metode SNI 1732-1989-F adalah untuk lapis permukaan (Laston MS $744=5$ $\mathrm{cm}$ ), untuk lapis pondasi (Laston MS $590=10 \mathrm{~cm}$ ) dan untuk lapis pondasi bawah (Batu Pecah Kelas $B$ CBR $80 \%=10 \mathrm{~cm})$ untuk masing - masing arah distribusi jalan Sukanagara - Tanggeung.
\end{abstract}

Kata kunci : Kapasitas jalan, perkerasan jalan, tebal perkerasasn

\section{PENDAhULUAN}

Seiring perkembangan jalan sebagai jaringan transportasi dan sebagai jaringan penghubung antar wilayah Cianjur Kota - Cianjur Selatan. Semakin meningkatnya pertumbuhan penduduk di kota kota dan semakin banyak kendaraan telah berdampak kepada masalah lalu lintas sehingga di tuntut lebih dalam mengenai perkembangan jalan dan semakin kesini banyak menimbulkan masalah lalu lintas yaitu kerusakan jalan, seperti kondisi jalan yang retak - retak dan jalan berlubang pada ruas jalan di sekitar jalur Cianjur Selatan tepatnya jalan ruas Sukanagara sampai Tanggeung Km Bdg 136+000 - Km Bdg 141+300 Kabupaten Cianjur dengan kondisi jalan seperti itu, maka tidak menutup kemungkinan akan menyebabkan kecelakaan lalu lintas, maka dari itu akan dikaji kapasitas dan tebal perkerasan pada ruas jalan Sukanagara - Tanggeung Km Bdg 136+000 - Km Bdg 141+300 Kabupaten Cianjur dan memberikan solusi dengan merencanakan kembali tebal perkerasan jalan yang bertujuan untuk mengurangi kecelakaan yang disebabkan oleh kondisi jalan yang retak - retak dan berlubang.

Dalam melakukan perhitungan kapasitas jalan dan perhitungan tebal perkerasan pada ruas jalan Sukanagara - Tanggeung Km Bdg 136+000 - Km Bdg 141+300 ini dengan menggunakan rumus rumus dan tabel - tabel yang tercantum dalam metode SNI 1732 - $1989-\mathrm{F}$.

Dari uraian diatas diperoleh sebuah permasalahan yang cukup menarik untuk diteliti mengenai penelitian ini, yaitu: 
1. Berapa kapasitas jalan pada ruas jalan Sukanagara - Tanggeung KM BDG 136+000 KM BDG 141+300 Kabupaten Cianjur?

2. Bagaimana cara merencanakan tebal perkerasan dengan metode SNI 1732 - 1989 F pada ruas jalan Sukanagara - Tanggeung KM BDG $136+000 \quad-\quad$ KM BDG $141+300$ Kabupaten Cianjur?

\section{METODOLOGI PENELITIAN}

\section{Lokasi Penelitian}

Lokasi penelitian ini adalah dokumen perencanaan jalan Sukanagara - Tanggeung. Peta lokasi tersebut dapat dilihat pada Gambar 1 dan peta rencana lokasi jalan Sukanagara - Tanggeung Kabupaten Cianjur pada Gambar 2.

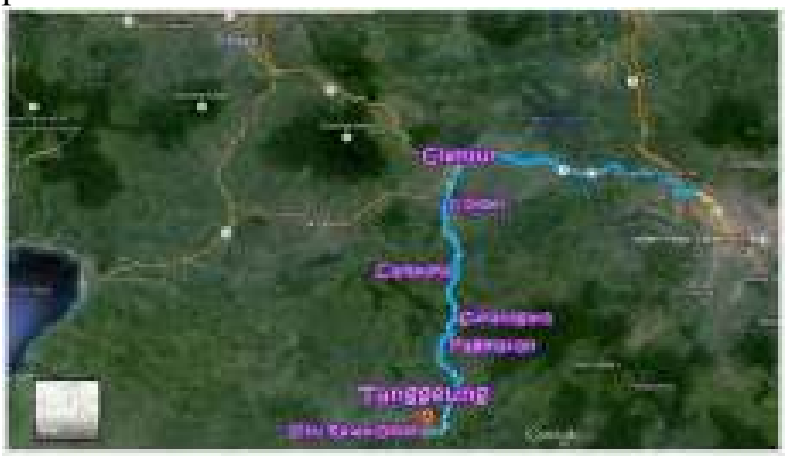

Gambar 1. Peta Lokasi penelitian

Sumber: google maps

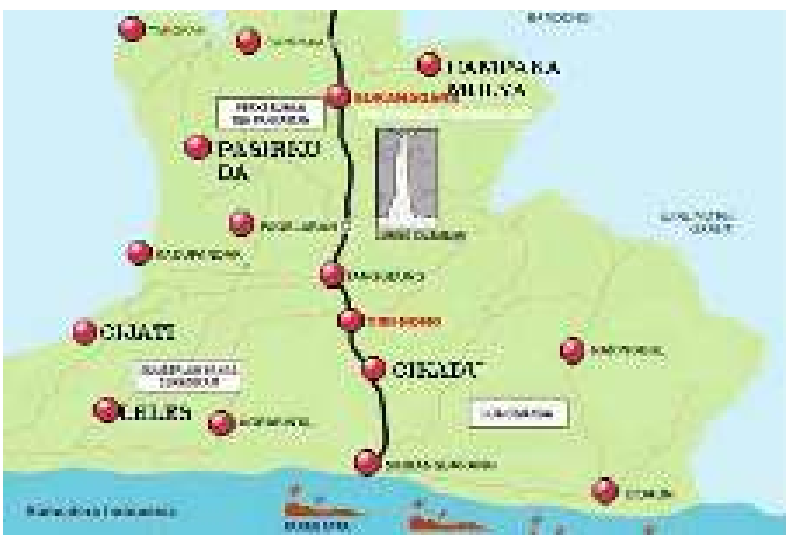

Gambar 2. Peta Rencana pada ruas jalan

Sukanagara - Tanggeung Km Bdg 125+000 -

Km Bdg 136+000 Kabupaten Cianjur akibat

jalan curam dan tikungan.

Sumber: google maps

\section{Jenis Dan Desain Penelitian}

metode penyelesaian masalah pada laporan penelitian ini adalah mengumpulkan data primer dan data sekunder, yaitu berupa data perencanaan jalan dari proyek jalan Cianjur Kota - Cianjur Selatan (sesuai lokasi objek penelitian), data lalu lintas harian rata - rata (LHR), data CBR tanah dan buku - buku perkuliahan. Mencari penyebab permasalahan pada ruas jalan Sukanagara Tanggeung KM BDG 136+000 - KM BDG $141+300$ Kabupaten Cianjur itu sendiri dengan cara menyurvey lokasi serta mencari dan menganalisa penyebab permasalahan pada ruas jalan Sukanagara - Tanggeung KM BDG 136+000 - KM BDG $141+300$. Mencari data yang di butuhkan untuk merencanakan tebal perkerasan pada ruas jalan Sukanagara - Tanggeung KM BDG 136+000 - KM BDG 141+300 seperti data CBR tanah dan LHR jalan. Kemudian merencanakan dan menghitung tebal perkerasan pada ruas jalan Sukanagara Tanggeung KM BDG $136+000$ - KM BDG $141+300$ dengan menggunakan metode analisa komponen SNI 1732 - $1989-\mathrm{F}$.

3. Alur penelitian

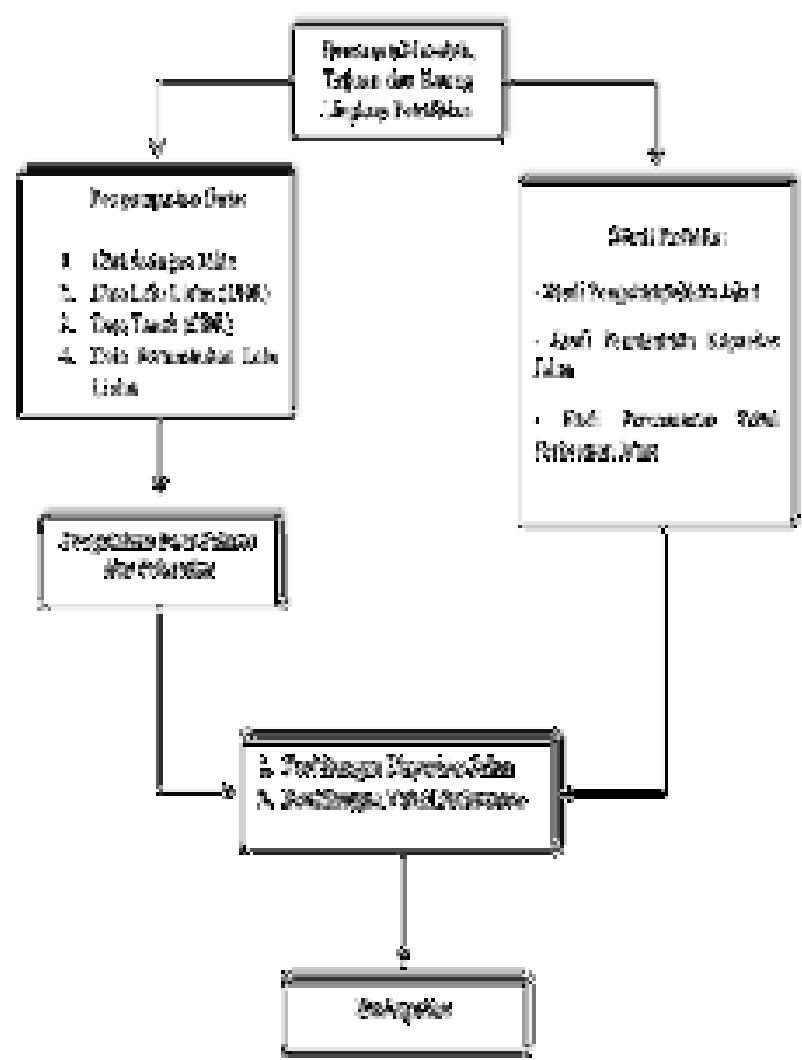

Gambar 3 Alur Penelitian

\section{Pengumpulan Data}

1. Data Primer

Data - data yang diambil dengan cara primer, yaitu:

- Melakukan pengukuran langsung ke lapangan terhadap jalan yang akan diteliti.

- Melakukan pengamatan langsung obyek penelitian di lapangan. 
- Melakukan peninjauan (Observasi) di lapangan secara langung.

- Menganalisis hasil - hasil data dari Dinas Bina Marga Propinsi Jawa Barat.

- Menanyakan (wawancara) langsung kepada warga masyarakat tentang kendala apa saja yang timbul di lapangan terhadap obyek penelitian.

- Pertumbuhan lalu lintas dan pertumbuhan umur rencana 7,5\% per tahun dari Dinas Bina Marga.

- Data LHR dari Dinas Bina Marga tahun 2013

2. Data Sekunder

Data - data yang diambil secara sekunder, adalah:

- Mengambil dari buku - buku perkuliahan.

- Mengambil dari buku - buku di perpustakaan yang berkaitan dengan ilmu teknik sipil.

- Didapat dari data - data hasil analisa pengolahan data.

\section{PEMBAHASAN}

a. Data Penelitian

\section{a. Data LHR}

Tabel 1 Data LHR 2013 Sukanagara - Tanggeung $(59.38 \mathrm{Km})$

\begin{tabular}{c|lc}
\hline No & Kelompok Kendaraan & $\begin{array}{c}\text { Jumlah } \\
\text { Kendaraan } \\
\text { Hari }\end{array}$ \\
\hline 1 & \multicolumn{1}{|c}{ Sepeda Motor } & 4664 \\
2 & Sedan Jeep & 643 \\
3 & Kendaraan Serbaguna & 648 \\
& Penumpang & \\
4 & Kendaraan Serbaguna & 729 \\
& Barang & \\
5 & Bis Kecil (Solar) dan & 0 \\
& Bis Besar & \\
6 & Truck Ringan 2 As & 272 \\
7 & Truck Sedang 2 As & 164 \\
8 & Truck 3 As & 0 \\
9 & Truck 4 As & 57 \\
10 & Trailler dan Semi & 0 \\
& Trailler & 7177 \\
\hline
\end{tabular}

Tabel 4.2 Data LHR 2015 dengan pertumbuhan lalu lintas $7.5 \%$ pertahun pada ruas jalan Sukanagara - Tanggeung

\begin{tabular}{|c|c|c|c|}
\hline No & $\begin{array}{l}\text { Kelompok } \\
\text { Kendaraan }\end{array}$ & $\begin{array}{c}\text { Jumlah } \\
\text { Kend/Hari } \\
\text { (2014) }\end{array}$ & $\begin{array}{c}\text { Jumlah } \\
\text { Kend/Hari } \\
\text { (2015) }\end{array}$ \\
\hline 1 & Sepeda Motor & 5014 & 5390 \\
\hline 2 & Sedan Jeep & 692 & 744 \\
\hline 3 & $\begin{array}{l}\text { Kendaraan } \\
\text { Serbaguna } \\
\text { Penumpang }\end{array}$ & 697 & 750 \\
\hline 4 & $\begin{array}{l}\text { Kendaraan } \\
\text { Serbaguna } \\
\text { Barang }\end{array}$ & 784 & 843 \\
\hline 5 & $\begin{array}{l}\text { Bis Kecil } \\
\text { (Solar) dan } \\
\text { Bis Besar }\end{array}$ & 0 & 0 \\
\hline 6 & $\begin{array}{l}\text { Truck Ringan } \\
2 \text { As }\end{array}$ & 293 & 315 \\
\hline 7 & $\begin{array}{l}\text { Truck Sedang } \\
2 \text { As }\end{array}$ & 177 & 191 \\
\hline 8 & Truck 3 As & 0 & 0 \\
\hline 9 & Truck 4 As & 62 & 67 \\
\hline 10 & $\begin{array}{l}\text { Trailler dan } \\
\text { Semi Trailler }\end{array}$ & 0 & 0 \\
\hline & JUMLAH & 7719 & 8300 \\
\hline
\end{tabular}

Sumber: Hasil Pengolahan Data

Dari data hasil survey Dinas Bina Marga Provinsi Jawa Barat tahun 2013 dan dikembangkan dengan pertumbuhan lalu lintas $7.5 \%$ pertahun yang dilakukan pada ruas jalan Sukanagara - Tanggeung untuk kedua arah diperoleh data volume lalu lintas tahunan pada tahun 2015 yaitu sebagai berikut: Dari data diatas, maka QLHRT rencana adalah: QLHRT $=\frac{8300 \times 365}{365}=8300 \mathrm{Ken} / \mathrm{Hari} / 2 \mathrm{Arah}$ Arah $1=1 / 2$ QLHRT x $100 \%=1 / 2 \times 8300 \times 100 \%$ $=50 \%$

Arah $2=1 / 2$ QLHRT $\times 100 \%=1 / 2 \times 8300 \times 100 \%$ $=50 \%$

Menentukan komposisi tiap jenis kendaraan

Tabel 3 Komposisi Tiap Jenis Kendaraan Total Kedua Arah (Kend./hari)

\begin{tabular}{c|cccccc}
\hline & \multicolumn{5}{|c}{ Golongan Kendaraan } & Tota \\
\cline { 2 - 5 } & MC & \multicolumn{4}{c}{ LV } & \multicolumn{2}{c}{ MHV } & $l$ \\
& Sepe & Mob & Kend. & Tru & Tru & \\
& da & il & Penum & ck & ck & \\
& Mot & Prib & pang & 2 & 4 & \\
$\sum_{\text {Kendaraa }}$ & or & adi & & As & As & \\
n/hari & 539 & 744 & 1593 & 506 & 67 & 830 \\
$\begin{array}{c}\text { Persentase } \\
(\%)\end{array}$ & 64.9 & 8.96 & 19.19 & 6.1 & 0.8 & 100. \\
& 4 & & & 0 & 1 & 00 \\
\hline
\end{tabular}

Sumber: Hasil Pengolahan Data 


\section{b. Data CBR dan Daya Dukung Tanah}

Dalam menentukan nilai CBR tanah dasar ini diambil dari data CBR Dinas Bina Marga Provinsi Jawa Barat tahun 2013 untuk ruas jalan Sukanagara - Tanggeung Kabupaten Cianjur.

Tabel 4 Nilai CBR Ruas Jalan Sukanagara Tanggeung

\begin{tabular}{c|ccc|}
\hline \multicolumn{4}{c|}{ CBR Tanah Sukanagara - Tanggeung } \\
\hline STA & CBR (\%) & STA & CBR (\%) \\
$136+000$ & 2.40 & $138+200$ & 3.40 \\
$136+200$ & 2.40 & $138+400$ & 3.50 \\
$136+400$ & 4.00 & $138+600$ & 3.20 \\
$136+600$ & 3.50 & $138+800$ & 3.00 \\
$136+800$ & 3.40 & $139+000$ & 2.90 \\
$137+000$ & 3.50 & $139+200$ & 2.60 \\
$137+200$ & 3.40 & $139+400$ & 2.70 \\
$137+400$ & 3.50 & $139+600$ & 3.80 \\
$137+600$ & 3.80 & $139+800$ & 3.70 \\
$137+800$ & 3.50 & $140+000$ & 3.80 \\
$138+000$ & 3.40 & & \\
\hline
\end{tabular}

Sumber: Dinas Bina Marga Provinsi Jawa Barat

Karena yang dibutuhkan adalah nilai CBR yang mewakili, maka untuk menentukannya penyusun menyajikan dengan cara grafis yaitu:

Tabel 5 Nilai CBR Jumlah dan Persentase yang Sama / Lebih Besar

\begin{tabular}{|c|c|c|}
\hline$C B R$ & $\begin{array}{c}\sum \text { yang sama } \\
\text { lebih besar }\end{array}$ & $\begin{array}{c}\% \text { yang sama / } \\
\text { lebih besar }\end{array}$ \\
\hline 2.40 & 21 & $\begin{array}{c}21 / 21 \times 100 \%= \\
100 \%\end{array}$ \\
\hline 2.60 & 19 & $\begin{array}{c}19 / 21 \times 100 \%= \\
90.48 \%\end{array}$ \\
\hline 2.70 & 18 & $\begin{array}{c}18 / 21 \times 100 \%= \\
85.71 \%\end{array}$ \\
\hline 2.90 & 17 & $\begin{array}{c}17 / 21 \times 100 \%= \\
80.95 \%\end{array}$ \\
\hline 3.00 & 16 & $\begin{array}{c}16 / 21 \times 100 \%= \\
76.19 \%\end{array}$ \\
\hline 3.20 & 15 & $\begin{array}{c}15 / 21 \times 100 \%= \\
71.43 \%\end{array}$ \\
\hline 3.40 & 14 & $\begin{array}{c}14 / 21 \times 100 \%= \\
66.67 \%\end{array}$ \\
\hline 3.50 & 10 & $\begin{array}{c}10 / 21 \times 100 \%= \\
47.62 \%\end{array}$ \\
\hline 3.70 & 5 & $\begin{array}{c}5 / 21 \times 100 \%= \\
23.81 \%\end{array}$ \\
\hline 3.80 & 4 & $\begin{array}{c}4 / 21 \times 100 \%= \\
19.05 \%\end{array}$ \\
\hline 4.00 & 1 & $\begin{array}{c}1 / 21 \times 100 \%= \\
4.76 \%\end{array}$ \\
\hline
\end{tabular}

\section{Sumber: Hasil Pengolahan Data}

Sehingga didapat nilai CBR yang mewakili sebesar 2.60, maka daya dukung tanahnya (DDT) ditentukan dengan rumus:

$$
\begin{gathered}
D D T=4.3 \log (C B R)+1.7 \\
D D T=4.3 \log (2.60)+1.7 \\
\\
\mathbf{D D T}=\mathbf{3 . 4 8}
\end{gathered}
$$

\section{c. Menentukan Sumbu Kendaraan}

Untuk perhitungan beban sumbu kendaraan pada perhitungan dibawah ini:

- Untuk kendaraan ringan roda tunggal pada ujung sumbu $50 \%$ - $50 \%$

- Untuk bus kecil roda tunggal pada ujung sumbu $34 \%$ dan roda ganda pada ujung sumbu $66 \%$.

- Untuk truck 2 as sumbu (small truck) roda tunggal pada ujung sumbu $34 \%$ dan roda ganda pada ujung sumbu $66 \%$.

- Untuk truck 2 as sumbu (large truck) roda tunggal pada ujung sumbu $34 \%$ dan roda ganda pada ujung sumbu $66 \%$.

- Untuk truck 4 as sumbu roda tunggal pada ujung sumbu $25 \%$ dan roda ganda pada ujung sumbu $75 \%$.

d. Klasifikasi dan Fungsi Jalan

Tabel 6 Klasifikasi dan Fungsi Jalan

\begin{tabular}{c|cc}
\hline $\begin{array}{c}\text { Klasifikasi } \\
\text { Fungsi }\end{array}$ & Kelas & $\begin{array}{c}\text { LHR (dalam } \\
\text { SPM/hari) }\end{array}$ \\
\hline Utama & I & $>20000$ \\
Sekunder & II A & $6000-20000$ \\
& II B & $1500-8000$ \\
Penghubung & II C & $<2000$ \\
\hline
\end{tabular}

\section{Sumber: Peraturan Perencanaan Geometrik} Jalan Raya No.13 Tahun 1970

\section{b. Perhitungan Kapasitas Jalan}

\section{a. Data - Data}

- Geometri:

Lebar jalur lalu lintas efektif: 5 m,Lebar bahu jalan: 2 x $1 \mathrm{~m}$, Tanpa median.

- Lalu Lintas:

- Distribusi arah lalu lintas : 50 / 50

- Pertumbuhan lalu lintas pertahun : 7.5 $\%$

- $\quad$ Volume lalu lintas per hari: VJR $=\mathrm{k} x$ LHRT

- $\quad \mathrm{VJR}=$ Volume Jam Rencana 
- LHRT = Lintasan harian rata-rata tahunan

- $\quad \mathrm{k}=$ proporsi lalu lintas harian yang terjadi selama periode puncak 0,1

- Kendaraan pribadi dan kendaraan penumpang (QLV)

- $\quad$ LHRT LV = $2337 \mathrm{kend}$./hari/2 arah

- $\mathrm{QLV}=0.1$ x $2337=234 \mathrm{kend} . / \mathrm{jam}$

- Kendaraan berat truck 2 As dan 4 As (QMHV / QHV)

- $\quad$ LHRT HV = 573 kend./hari $/ 2$ arah

- $\mathrm{QHV}=0.1 \times 573=58 \mathrm{kend} . / \mathrm{jam}$

- Kendaraan roda dua / sepeda motor (QMC)

- $\quad$ LHRT MC $=5390 \mathrm{kend} . / \mathrm{hari} / 2$ arah

- $\mathrm{QMC}=0.1 \times 5390=539 \mathrm{kend} . / \mathrm{jam}$

- Lingkungan:

- Ukuran kota $<1.000 .000$ penduduk

- Beberapa angkutan umum

- Beberapa pejalan kaki

- Beberapa kendaraan keluar masuk di sisi jalan.

\section{c. Langkah - Langkah Perhitungan} Kapasitas

a. Menentukan jenis jalan:

Tabel 7. Jenis Jalan

\begin{tabular}{|c|c|c|c|}
\hline \multirow{3}{*}{$\begin{array}{l}\text { Lebar Jalur } \\
\text { Efektif } \\
\text { WC } \\
\text { (m) }\end{array}$} & \multirow{3}{*}{$\begin{array}{c}\text { Jumlah } \\
\text { Lajur }\end{array}$} & \multicolumn{2}{|c|}{ Jenis Jalan } \\
\hline & & \multicolumn{2}{|c|}{ Median } \\
\hline & & $\begin{array}{l}\text { Ada } \\
\text { (Divided) }\end{array}$ & $\begin{array}{l}\text { Tidak } \\
\text { (Undivided) }\end{array}$ \\
\hline $5-10,5$ & 2 & $2 / 2$ & $2 / 2 \mathrm{UD}$ \\
\hline $10,5-16$ & 4 & $4 / 2$ & $4 / 2 \mathrm{UD}$ \\
\hline \multicolumn{4}{|c|}{$\begin{array}{c}\text { Sumber: Tata Cara Perencanaan Tebal } \\
\text { Perkerasan Lentur Jalan Raya dengan Metode } \\
\text { SNI 1732-1989-F }\end{array}$} \\
\hline \multirow{2}{*}{\multicolumn{4}{|c|}{$\begin{array}{ll}\text { - } & \mathrm{Wc}=5 \mathrm{~m}(5-10,5) \mathrm{m} \\
\text { - } & \text { Jumlah } 2 \text { lajur } 2 \text { arah } \\
\text { - } & \text { Tanpa median (UD) jalan: } 2 / 2 \mathrm{UD}\end{array}$}} \\
\hline & & & \\
\hline \multicolumn{4}{|c|}{ Tabel 8. Ukuran Kota } \\
\hline \multicolumn{2}{|c|}{$\begin{array}{l}\text { Ukuran Kota } \\
\text { (Juta pend.) }\end{array}$} & \multicolumn{2}{|c|}{$\begin{array}{l}\text { Kelas Ukuran } \\
\text { Kota }\end{array}$} \\
\hline \multicolumn{2}{|c|}{$<$} & \multicolumn{2}{|l|}{ Sangat Kecil } \\
\hline \multicolumn{2}{|c|}{$0,1-0,5$} & Kecil & \\
\hline \multicolumn{2}{|c|}{$0,5-1,0$} & Sedang & \\
\hline \multicolumn{2}{|c|}{$1,0-3,0$} & Besar & \\
\hline
\end{tabular}

\begin{tabular}{c}
\hline Sangat Besar \\
\hline Sumber: Tata Cara Perencanaan Tebal
\end{tabular}

Sumber: Tata Cara Perencanaan Tebal

Perkerasan Lentur Jalan Raya dengan Metode SNI 1732-1989-F

Ukuran kota $<1.000 .000$ penduduk $(0,5-1,0)$ juta Kelas ukuran kota $(\mathrm{CS})=$ Sedang

c. Menentukan hambatan samping (SFC)

Tabel 9. Kelas Hambatan Samping untuk Jalan Perkotaan

\begin{tabular}{|c|c|c|c|}
\hline $\begin{array}{c}\text { Kelas } \\
\text { Hambatan } \\
\text { Samping } \\
\text { (SFC) }\end{array}$ & $\begin{array}{l}\text { Ko } \\
\text { de }\end{array}$ & $\begin{array}{c}\text { Jumlah } \\
\text { Berbobot } \\
\text { kejadian per } \\
200 \text { m perjam } \\
\text { (Nı cicil }\end{array}$ & Kondisi Khusus \\
\hline $\begin{array}{l}\text { Sangat } \\
\text { rendah }\end{array}$ & $\begin{array}{l}\text { V } \\
\text { L }\end{array}$ & $\begin{array}{l}< \\
1 \\
0 \\
n\end{array}$ & $\begin{array}{l}\text { Daerah } \\
\text { permukiman; jalan } \\
\text { samping tersedia }\end{array}$ \\
\hline Rendah & $\mathrm{L}$ & $100-299$ & $\begin{array}{l}\text { Daerah } \\
\text { permukiman } \\
\text {; beberapa } \\
\text { angkutan } \\
\text { umum dsb }\end{array}$ \\
\hline Sedang & M & $300-499$ & $\begin{array}{l}\text { Daerah industri; } \\
\text { beberapa toko di } \\
\text { sisi jalan }\end{array}$ \\
\hline Tinggi & $\mathrm{H}$ & $500-899$ & $\begin{array}{l}\text { Daerah komersial; } \\
\text { aktivitas sisi jalan } \\
\text { tinggi }\end{array}$ \\
\hline $\begin{array}{c}\text { Sangat } \\
\text { tinggi }\end{array}$ & $\begin{array}{l}\text { V } \\
H\end{array}$ & $\begin{array}{l}> \\
9 \\
0\end{array}$ & $\begin{array}{l}\text { Daerah komersial; } \\
\text { aktivitas pasar di } \\
\text { sisi jalan }\end{array}$ \\
\hline
\end{tabular}

Sumber: Tata Cara Perencanaan Tebal Perkerasan Lentur Jalan Raya dengan Metode SNI 1732-1989-F

Berdasrkan data dilapangan ada beberapa angkutan umum, beberapa pejalan kaki, beberapa kendaraan keluar masuk di sisi jalan, Kelas hambatan samping $(\mathrm{SFC})=\mathrm{L}($ rendah $)$

d. Menentukan ekivalensi mobil penumpang (EMP)

$\mathrm{Q}$ total $=\mathrm{QLV}+\mathrm{QHV}+\mathrm{QMC}$ $=234+58+539=831 \mathrm{kend} . / \mathrm{jam} / 2$ arah

$\mathrm{EMP}_{\mathrm{LV}}=1.0$

$\mathrm{EMP}_{\mathrm{HV}}=1.3$

$\mathrm{EMP}_{\mathrm{MC}}=0.5$

$\mathrm{Q}$ total $=\mathrm{Q}_{\mathrm{LV}} \cdot \mathrm{EMP}_{\mathrm{LV}}+\mathrm{Q}_{\mathrm{HV}} \cdot \mathrm{EMP}_{\mathrm{HV}}+\mathrm{Q}_{\mathrm{MC}}$. $\mathrm{EMP}_{\mathrm{MC}}$

$$
\begin{aligned}
& =(234 \times 1.0)+(58 \times 1.3)+(539 \times 0.5) \\
& =580 \mathrm{SMP} / \mathrm{jam}
\end{aligned}
$$

e. Analisis kecepatan arus bebas $\left(\mathrm{FV}_{\mathrm{LV}}\right)$ 
$\mathrm{FV}_{\mathrm{LV}}=\left(\mathrm{FV}_{\mathrm{O}}+\mathrm{FV}_{\mathrm{W}}\right) \times \mathrm{FFV}_{\mathrm{SF}}+\mathrm{FFV}_{\mathrm{CS}}$

- Tabel 2.1.6:2/2 UD : $\mathrm{FV}_{\mathrm{LV}}: \mathrm{FV}_{\mathrm{O}}=44 \mathrm{Km} / \mathrm{jam}$

- Tabel 2.1.7 : 2/2 UD : $\mathrm{Wc}=5 \mathrm{~m}: \mathrm{FV}_{\mathrm{W}}=-9.5$

- $\quad$ Tabel $2.1 .8: 2 / 2 \mathrm{UD}: \mathrm{SFC}=\mathrm{L}: \mathrm{Ws}=1.0$ : $\mathrm{FFV}_{\mathrm{SF}}=0.98$

- Tabel 8 : Ukuran kota $<1.000 .000: \mathrm{FFV}_{\mathrm{CS}}=$ 0.95

- Untuk rumus jalan luar kota, ukuran kota diabaikan (Sumber: $M K J$ )

$\mathrm{FV}_{\mathrm{LV}}=\left(\mathrm{FV}_{\mathrm{O}}+\mathrm{FV}_{\mathrm{W}}\right) \times \mathrm{FFV}_{\mathrm{SF}}$ $=(44-9.5) \times 0.98=33.81 \mathrm{Km} / \mathrm{jam}$

f. Menghitung kapasitas (C)

$\mathrm{C}=\mathrm{Co} \times \mathrm{FC}_{\mathrm{SP}} \times \mathrm{FC}_{\mathrm{W}} \times \mathrm{FC}_{\mathrm{SF}} \times \mathrm{FC}_{\mathrm{CS}}$

- Tabel 2.1.11: 2/2 UD : $\mathrm{C}_{\mathrm{O}}=2900 \mathrm{SMP} / \mathrm{jam} / 2$ arah

- $\quad$ Tabel 2.1.12: 2/2 UD : Distribusi $50-50: \mathrm{FC}_{\mathrm{SP}}$ $=1.0$

- $\quad$ Tabel $2.1 .13: 2 / 2 \mathrm{UD}: \mathrm{Wc}=5 \mathrm{~m}: \mathrm{FC}_{\mathrm{W}}=0.56$

- $\quad$ Tabel 2.1.14:2/2 UD : $\mathrm{SFC}=\mathrm{L}: \mathrm{Ws}_{\mathrm{s}}=1.0$ : $\mathrm{FC}_{\mathrm{SF}}=0.94$

- $\quad$ Tabel 2.1.16 : Ukuran kota 1.000.000 : $\mathrm{FC}_{\mathrm{CS}}=$ 0.94

- Untuk rumus jalan luar kota, ukuran kota diabaikan (Sumber: MKJI)

$\mathrm{C}=\mathrm{Co} \times \mathrm{FC}_{\mathrm{SP}} \times \mathrm{FC}_{\mathrm{W}} \times \mathrm{FC}_{\mathrm{SF}}$

$=2900 \times 1.0 \times 0.56 \times 0.94=1527 \mathrm{SMP} / \mathrm{jam}$

g. Menentukan analisis kejenuhan lalu lintas Derajat kejenuhan (DS)

$$
\mathrm{DS}=\frac{Q}{C}=\frac{831}{1527}=0.54
$$

h. Kecepatan kendaraan ringan sesungguhnya Dari grafik D-2:1 (Kecepatan sebagai fungsi dari DS untuk jalan 2/2 UD Untuk $\mathrm{FV}_{\mathrm{LV}}=$ 33.81 Km/jam dan DS $=0.54$ Maka didapat kecepatan kendaraan ringan sesungguhnya $\left(\mathrm{V}_{\mathrm{LV}}\right) \mathrm{V}_{\mathrm{LV}}=29 \mathrm{Km} / \mathrm{jam}$

i. Hasil perhitungan kapasitas dengan nilai Derajat Kejenuhan $(\mathrm{DS}=0.54)$ dan $\mathrm{FV}_{\mathrm{LV}}=$ 33.81 Km/jam serta menurut Peraturan Menteri Perhubungan No.KM 14 tahun 2006, yaitu:

- Dengan nilai $\mathrm{DS}=0.54(\mathrm{DS} \leq 0.6)$ seharusnya kecepatan perjalanan rata - rata $\geq 80 \mathrm{~km} / \mathrm{jam}$. Karena $\mathrm{FV}_{\mathrm{LV}}=33.81$ $\mathrm{km} / \mathrm{jam}$, maka pada ruas jalan tersebut perlu diperlebar.

- Dengan kecepatan kendaraan ringan sesungguhnya $29 \mathrm{~km} / \mathrm{jam}$ ( $\leq 30 \mathrm{~km} / \mathrm{jam}$ ), maka jalan tersebut mendekati arus tidak stabil.

- $\quad$ Arus lalu lintas mendekati tidak stabil.

\section{d. Perhitungan Tebal Perkerasan} Data - Data

- Klasifikasi dan fungsi jalan: Kolektor II B

- Jenis jalan tanpa median: 2/2 UD

- Jumlah jalur : 2 jalur / 2 lajur / 2 arah

- Lebar jalur lalu lintas efektif : $7 \mathrm{~m}$

- Lebar bahu jalan :2 x $1 \mathrm{~m}$

- Distribusi arah lalu lintas : 50 / 50

- Ukuran kota : < 1.000.000 penduduk

- Kelas hambatan samping : Rendah (L)

- Data lalu lintas : Tahun 2013

- $\quad$ CBR : 2,60

- $\quad$ DDT : 4,3 log (CBR) + 1,7 = 3,48

- Jalan direncanakan dibuka tahun : 2016

- Umur rencana jalan : 5 tahun

- Pertumbuhan lalu lintas (i) Selama pelaksanaan $\quad: 7.5 \%$

- Pertumbuhan lalu lintas (i) Umur rencana : $7.5 \%$

- $\quad$ Faktor regional (FR) tabel 2.2.4: 0.5

- Kelandaian datar $(<3 \%) \quad:<6 \%$

- Persentase kendaraan berat $: \leq 30 \%$

- Curah hujan : <900 mm/th

- Koefisien distribusi kendaraan (C) : 0.5

e. Langkah - Langkah Perhitungan Tebal Perkerasan

a. Data LHR tahun 2013:

- Kendaraan ringan 2 ton $=2020 \mathrm{Kend}$. $/$ hari

- Truck 2 As 10 ton $=436 \mathrm{Kend}$. $/$ hari

- Truck 4 As 15 ton = 57 Kend./hari $\sum$ LHR $2013=2513$ Kend.$/$ hari

b. LHR pada tahun 2016 (awal umur rencana) dengan rumus:

LHR awal $=\sum$ Kend. $\mathrm{x}(1+\mathrm{i})^{\mathrm{UR}}$

- Kendaraan ringan 2 ton $=2020 \times(1+7.5$ $=2510$ kend./hari

- $\quad$ Truck 2 As 10 ton $=436 \times(1+7.5 \%)$ $=542$ kend./hari

- $\quad$ Truck 4 As 15 ton $=57 \times(1+7.5 \%)^{3}$ $=71$ kend./hari

- $\quad$ LLHR $2016=3123 \mathrm{kend} . / \mathrm{hari}$

c. LHR pada tahun 2021 (akhir umur rencana) dengan rumus:

LHR akhir $=$ LHR awal $\times(1+\mathrm{i})^{\mathrm{UR}}$

- Kendaraan ringan 2 ton $=2510 \times(1+7.5 \%)^{5}$ $=3604$ kend./hari

- $\quad$ Truck 2 As 10 ton $=542 \times(1+7.5 \%)^{5}$ $=778$ kend./hari

- $\quad$ Truck 4 As 15 ton $=71 \times(1+7.5 \%)^{5}$ $=102$ kend./hari $\sum$ LHR $2021=4484$ kend. $/$ hari 
d. LHR satuan mobil penumpang: LHRsmp $=\mathrm{LHR}_{2021} \mathrm{x}$ faktor ekivalen

- Kendaraan ringan 2 ton $=3604 \times 1.0$ $=3604$ kend. /hari

- Truck 2 As 10 ton $=778 \times 1.2$ $=934$ kend.$/$ hari

- Truck 4 As 15 ton $=102 \times 1.2$ $=123$ kend. $/$ hari

¿LHRsmp $=4661 \mathrm{kend} . /$ hari

e. Menentukan sumbu kendaraan:

Tabel 4.7 Beban Sumbu masing - masing Kendaraan

\begin{tabular}{c|cccc}
\hline No & Jenis & Berat & Sumbu & Sumb \\
& Kendaraa & Maksima & Tungga \\
$n$ & $l$ & $l$ & $\begin{array}{c}u \\
\text { Gand } \\
a\end{array}$ \\
& & & & - \\
\hline 1 & Kendaraan & 2 ton & $50 \%$ & - \\
& Ringan & & 1 ton & - \\
2 & Truck 2 & 10 ton & $34 \%$ & $66 \%$ \\
& As & & 3.4 ton & 6.6 \\
& & & & ton \\
3 & Truck 4 & 15 ton & $25 \%$ & $75 \%$ \\
& As & & 3.75 & 11.25 \\
& & & ton & ton \\
\hline
\end{tabular}

\section{Sumber: Hasil Pengolahan Data}

f. Menentukan angka ekivalen (E):

$$
\begin{gathered}
E_{\text {tunggal }}=\left(\frac{L}{8.16}\right)^{4} \\
E_{\text {ganda }}=0.086\left(\frac{L}{8.16}\right)^{4}
\end{gathered}
$$

- Angka ekivalen untuk kendaraan ringan dari tabel 2.2.3 $(\mathrm{E}=0.0002)$

- Angka ekivalen untuk truck 2 as:

$$
\begin{array}{lll}
\mathrm{E}_{\text {tunggal }} & =\left(\frac{3.4}{8.16}\right)^{4} & =0.0301 \\
\mathrm{E}_{\text {ganda }} & =0.086\left(\frac{6.6}{8.16}\right)^{4} & =0.0368
\end{array}
$$

- Angka ekivalen untuk truck 4 as:

$$
\begin{array}{lll}
\mathrm{E}_{\text {tunggal }} & =\left(\frac{3.75}{8.16}\right)^{4} & =0.0446 \\
\mathrm{E}_{\text {ganda }} & =0.086\left(\frac{11.25}{8.16}\right)^{4}=0.3107
\end{array}
$$

- Kendaraan ringan 2 ton

$$
(E)=0.0002+0.0002 \quad=0.0004
$$

- Truck 2 As 10 ton

$$
(\mathrm{E})=0.0301+0.0368 \quad=0.0669
$$

- Truck 4 As 15 ton $(\mathrm{E})$ $=0.0446+0.3107=0.3553$

g. Menghitung lintas ekivalen permulaan (LEP) dengan rumus:

$$
\mathrm{LEP}=\mathrm{LHR} \text { awal } \times \mathrm{C} \times \mathrm{E}
$$

- $\quad$ Kendaraan ringan 2 ton $=2510 \times 0.5 \times$ $0.0004=0.50$

- $\quad$ Truck 2 As 10 ton $=542 \times 0.5 \times 0.0669$ $=18.13$

- $\quad$ Truck 4 As 15 ton $=71 \times 0.5 \times 0.3553$ $=12.61$ $\sum$ LEP $=31.24$

h. Menghitung lintas ekivalen akhir (LEA) dengan rumus:

LEA $=$ LHR akhir $\times \mathrm{C} \times \mathrm{E}$

- Kendaraan ringan 2 ton $=3604 \times 0.5 \times 0.0004$ $=0.72$

- $\quad$ Truck 2 As 10 ton $=778 \times 0.5 \times 0.0669$ $=26.02$

- $\quad$ Truck 4 As 15 ton $=102 \times 0.5 \times 0.3553$

$=18.12$

$\sum$ LEA $\quad=44.86$

i. Menghitung lintas ekivalen tengah (LET) dengan rumus:

$$
\begin{gathered}
\text { LET }=\frac{1}{2}(\text { LEP }+ \text { LEA }) \\
\text { LET }=\frac{1}{2}(31.24+44.86)=38.05
\end{gathered}
$$

j. Menghitung lintas ekivalen rencana (LER) dengan rumus:

$$
\begin{aligned}
& \text { LER }=\operatorname{LET}\left(\frac{\text { Umur Rencana }}{10}\right) \\
& \text { LER }=38.05\left(\frac{5}{10}\right)=19.025
\end{aligned}
$$

k. Mencari nilai Indeks Tebal Perkerasan (ITP) Dengan data sebagai berikut:

- $\mathrm{CBR}=2.60$ maka didapat nilai $\mathrm{DDT}=3.48$

- $\mathrm{IPt}=(1.5-2.0)$ di ambil 1.5 dari tabel 2.2.5 dengan nilai LER $=19.025$ dan Klasifikasi jalannya Kolektor.

- $\quad \mathrm{FR}=0.5$ dari tabel 2.2.4 untuk kelandaian medan $<6 \%$, persentase kendaraan berat $\leq$ $30 \%$ dan curah hujan $<900 \mathrm{~mm} / \mathrm{th}$.

- Untuk LER ini direncanakan lapis permukaan dengan Laston MS $744($ IPo = 3.9 - 3.5) dari tabel 2.2.6 maka untuk mencari ITP digunakan Nomogram 5.

- Dari Nomogram 5 , maka didapat ITP = 6.00

1. Menentukan Tebal Perkerasan

Umur rencana 5 tahun: Koefisien kekuatan relatif (a) untuk masing - masing lapisan perkerasan jalan. a1 $\rightarrow$ lapis permukaan (Laston MS $744=0.40$ ) a2 $\rightarrow$ lapis pondasi (Laston MS 590 $=0.35$ ) a3 $\rightarrow$ lapis pondasi bawah (Batu Pecah Kelas B / CBR $80 \%=0.13$ ) 
m. minimum tebal perkerasan untuk ITP $=6.00$

- Lapis permukaan (Laston MS 744)

$\rightarrow \mathrm{D} 1 \mathrm{~min} .=5 \mathrm{~cm}$

- Lapis pondasi (Laston MS 590)

$\rightarrow \mathrm{D} 2 \mathrm{~min} .=10 \mathrm{~cm}$

- Lapis pondasi bawah (Batu Pecah Kelas B)

$$
\rightarrow \mathrm{D} 3 \mathrm{~min} .=10 \mathrm{~cm}
$$

- $\mathrm{ITP}=(\mathrm{a} 1 \times \mathrm{D} 1)+(\mathrm{a} 2 \times \mathrm{D} 2)+(\mathrm{a} 3 \times \mathrm{D} 3)$ $6.00=(0.40 \times 5)+(0.35 \times 10)+(0.13 \times \mathrm{D} 3)$

- $\mathrm{D} 3=3.85 \rightarrow 4 \mathrm{~cm}<\mathrm{D} 3$ min. $10 \mathrm{~cm}$, maka diambil D3 $=10 \mathrm{~cm}$

- $\mathrm{D} 2=7.71 \rightarrow 8 \mathrm{~cm}<\mathrm{D} 2$ min. $10 \mathrm{~cm}$, maka diambil D2 $=10 \mathrm{~cm}$

- $\mathrm{D} 1=5 \mathrm{~cm}$ (tebal minimum)

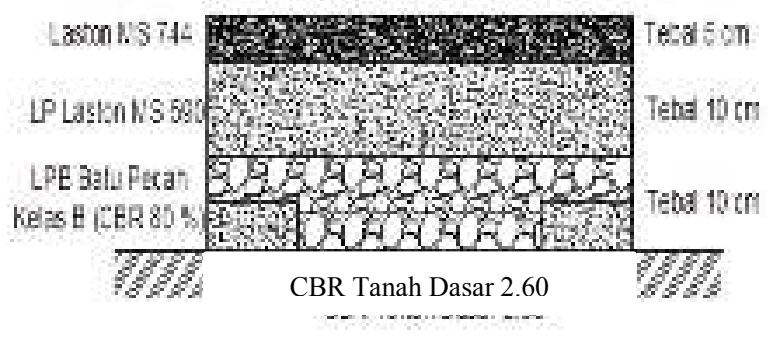

Gambar 3. Konstruksi Tebal Perkerasan Jalan

Sumber: Hasil Pengolahan Data

\section{KESIMPULAN}

Dalam pelaksanaan penyusunan laporan tugas akhir pada lokasi penelitian ruas jalan Sukanagara Tanggeung dengan judul tugas akhir "Kajian Kapasitas Dan Tebal Perkerasan Pada Ruas Jalan Sukanagara - Tanggeung Km Bdg 136+000 - Km Bdg 141+300 Kabupaten Cianjur". Penyusun selama melaksanakan penyusunan laporan tugas akhir ini mendapatkan kesimpulan, antara lain:

1. Kapasitas jalan pada ruas jalan Sukanagara Tanggeung dengan menggunakan metode SNI 1732 - 1989 - $F$ dengan rumus untuk jalan luar kota, yaitu $1527 \mathrm{SMP} / \mathrm{jam}$.

2. Dengan nilai derajat kejenuhan $\mathrm{DS}=0.54$ (DS $\leq 0.6)$ seharusnya kecepatan perjalanan rata rata $\geq 80 \mathrm{~km} / \mathrm{jam}$. Karena $\mathrm{FV}_{\mathrm{LV}}=33.81$ $\mathrm{km} / \mathrm{jam}$, maka pada ruas jalan tersebut perlu diperlebar.

3. Dengan kecepatan kendaraan ringan sesungguhnya $V_{L V}=29 \mathrm{~km} / \mathrm{jam}(\leq 30 \mathrm{~km} / \mathrm{jam})$, maka jalan tersebut mendekati arus lalu lintas tidak stabil.
4. Tebal perkerasan lentur yang dihitung dengan metode SNI 1732-1989-F adalah untuk lapis permukaan (Laston MS $744=5 \mathrm{~cm}$ ), untuk lapis pondasi (Laston MS $590=10 \mathrm{~cm}$ ) dan untuk lapis pondasi bawah (Batu Pecah Kelas B CBR $80 \%=10 \mathrm{~cm}$ ) untuk masing - masing arah distribusi jalan Sukanagara - Tanggeung.

\section{DAFTAR PUSTAKA}

SNI 1732 - 1989 - F, Perencanaan Tebal Perkerasan Lentur Jalan Raya, Penerbit Kementerian Pekerjaan Umum.

Direktorat Jenderal Bina Marga, 1997, Manual Kapasitas Jalan Indonesia, Penerbit Kementerian Pekerjaan Umum.

Departemen Pekerjaan Umum Direktorat Jendral Bina Marga. Spesipikasi Umum 2018 Untuk Pekerjaan Kontruksi Jalan dan Jembatan. Badan Penerbit Pekerjaan Umum. Jakarta: 2018.

Departemen Pekerjaan Umum Direktorat Jendral Bina Marga Jalan No.038/T/BM/1997 . Tatacara Perenca naan Geometrik Jalan Antar Kota. Badan Penerbit Pekerjaan Umum. Jakarta: 1997.

Departemen Pekerjaan Umum Direktorat Jendral Bina Marga. Petunjuk Perencanaan Tebal Perkerasan Lentur Jalan Raya Dengan Analisa Komponen. Badan Penerbit Pekerjaan Umum. Jakarta: 1989.

Silvia Sukirman. Dasar-dasar Perencanaan Geometrik Jalan, Nova. Bandung:1995. 